\title{
Adsorption and inactivation of proteolytic enzymes by Triaenophorus nodulosus (Cestoda)
}

\author{
G.I. IZVEKOVA*, T.V. FROLOVA, E.I. IZVEKOV
}

I.D. Papanin Institute for Biology of Inland Waters, Russian Academy of Sciences, Borok, Nekouzskii raion,

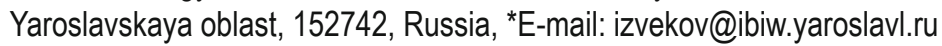

\section{Article info}

Received September 20, 2016 Accepted December 15, 2016

\section{Summary}

The proteolytic activity in washings off the Triaenophorus nodulosus cestode tegument and the ability of the worms to inactivate proteolytic enzymes were studied. It was found that the major proteolytic activity in the washing samples is represented by the easily desorbed fraction most probably characterizing the activity of the host's enzymes. Serine proteinases are an essential part of these enzymes. It was shown that the worms' incubation medium and their homogenates can inhibit host proteinases and commercial trypsin samples. Suppressive activity of the incubation medium suggests that the inhibitors are rather spontaneously produced by the worms than induced by the presence of proteinases in the surrounding medium. The inhibitor produced by the cestode is hypothesized to be trypsin-specific.

Keywords: fish; Cestodes; Triaenophorus nodulosus; digestive enzymes; proteolytic activity; proteinase inhibitors

\section{Introduction}

The intestine of vertebrates is an ideal environment for cestodes dwelling there, however, the tapeworms are constantly affected by destructive proteolytic enzymes. Intestinal parasites are less affected by the host's immune systems, but they should resist the action of digestive enzymes. One of the basic mechanisms protecting the tapeworms from the host's proteinases is inhibitor secretion (Soprunov, 1987; Pappas \& Uglem, 1990). The concept that parasites can use proteinase inhibitors to survive in the host is over 100 years old. Besides, it is becoming obvious that parasite inhibitors may control the host's immune response (Dzik, 2006; Knox, 2007). Proteinase inhibitors, as well as proteinases themselves, play an important role in the life cycle of parasites, their virulence and pathogenesis (Li et al., 2006; Hwang et al., 2009; Molehin et al., 2012; Rascón \& McKerrow, 2013). Inhibitors are produced by parasites to avoid proteolysis by host proteinases and thus survive. It is supposed that the specificity of parasites to hosts depends on the parasite proteinase inhibitors (Hawley \& Peanasky, 1992).

Ample research is devoted to proteinase inhibitors in a wide range of nematodes (for a review, see Knox, 2007). Similar studies focusing on cestodes are scarce; most papers were published long ago and mainly concern Hymenolepis diminuta or $\mathrm{H}$. microstoma (Pappas \& Read, 1972a; Pappas, 1978; Schroeder \& Pappas, 1980; Schroeder et al., 1981; Pappas, 1987; Pappas \& Uglem, 1990). In some cases the obtained data are contradictory. While inhibitors of all classes of proteinases (aspartyl, serine, cysteine and metalloproteinases) occurring at various stages of parasite life cycle have been discovered in nematodes (Hawley, Peanasky, 1992; Kageyama, 1998; Delaney et al., 2005; Knox, 2007), only inhibitors of serine proteinases (trypsin and chymotrypsin) have been found in cestodes (Matskási, 1984; Pappas, Uglem, 1990; Li et al. 2006) so far. It may be due to the differences in the life cycle of these groups of helminths and, consequently, the barriers bro-

\footnotetext{
$\bar{*}$ - corresponding author
} 
ken by the parasites to get into the host, as well as to insufficient information on inhibitors in cestodes.

Besides, attempts to detect inhibitor activity in cestodes or extract their proteinase inhibitors are not always successful. Thus, no proteinase inhibitors were found in Skrjabinia cesticillus from the chicken intestine and in Moniezia benedeni and M. expansa from the sheep intestine (Klimenko \& Ķĕniņa, 1971), and live cestodes M. expansa did not inhibit casein hydrolysis (Dubovskaya, 1973). Therefore it was supposed that the proteolytic enzyme inhibitor excreted by the helminths is not active enough to provide survival of worms (Shishova-Kasatochkina \& Leutskaya, 1979). The negative results of proteinase inhibitor research in the above-cited papers are probably caused by imperfect methods, which in some cases is admitted by the authors (Klimenko \& Kĕnina, 1971).

There are very few studies devoted to the ability of cestodes inhabiting the fish intestine to suppress host proteinases. It is reported that intact Proteocephalus longicollis from salmonids secretes the trypsin inhibitor into the surrounding medium (Reichenbach-Klinke \& Reichenbach-Klinke, 1970). It was ascertained that extracts from Bothriocephalus acheilognathi larvae and adult worms suppress the trypsin and chymotrypsin activity of the carp intestine in vitro (Matskási, 1984).

The present study was undertaken to evaluate the possibility that Triaenophorus nodulosus, a cestode common in pike, Esox lucius, can inactivate proteolytic enzymes.

\section{Material and Methods}

\section{Study objects}

The study was performed on cestodes Triaenophorus nodulosus (Pallas) from the intestine of pike, Esox lucius L. The tapeworms were taken from 17 pikes $310-680 \mathrm{~mm}$ long caught in the Rybinsk reservoir (Russian Federation, 58 $22^{\prime} 30^{\prime \prime} \mathrm{N} 38^{\circ} 28^{\prime} 04^{\prime \prime} \mathrm{E}$ ) during the spring season. In a single pike, the number of helminths was $2-4$ and their total weight varied from 0.27 to $2.11 \mathrm{~g}$ per an individual fish. The fish were caught by gill nets, transported to the laboratory in special containers with water, and immobilized by a blow on the head. The dissection of fish and their intestines, extraction of worms and sample preparation were performed on the ice bath.

\section{Sample preparation}

The fish intestines were dissected, the worms were extracted, randomly grouped into samples of similar weight $(0.4-0.7 \mathrm{~g}$ each), and then transferred to $10 \mathrm{ml}$ of Ringer's solution $(\mathrm{pH} \mathrm{7.5)}$ for cold-blooded animals. In total, 23 groups of worms were studied $(n=23)$. To remove the host enzymes adsorbed on the cestode surface, the worms were shaken for 30 seconds in Ringer's solution, then transferred to fresh solution twice and shaken for 15 min each time. As a result, three fractions of washings off the tegument were obtained: $F_{1}, F_{2}$ and $F_{3}$. A total of 7 groups of worms were used when measuring proteolytic activity in different fractions $(n=7)$.
Further, the worms were transferred to $10 \mathrm{ml}$ of fresh Ringer's solution and incubated for 24 hours at a temperature of $10^{\circ} \mathrm{C}$. During the entire incubation the worms remained alive. Five groups of worms were used to obtain the incubation medium $(n=5)$. After the incubation, the $\mathrm{pH}$ values were measured in the medium.

Next 11 groups ( $n=11$ ) of worms were homogenized, and the homogenate was diluted with Ringer's solution in the mass-volume ratio of 1:9.

Besides, the homogenate of the pike intestine mucosa was prepared. For this purpose, the intestines of 5 pikes ranged from 48 to $52 \mathrm{~cm}$ were used. After dissecting the intestine and extracting the chyme and the worms, the mucosa was removed with a plastic spatula, homogenized and diluted with Ringer's solution in the mass-volume ratio of 1:49. All homogenates were prepared using glass homogenizers made by Sartorius AG (Germany).

The worm and mucosa homogenates were centrifuged at $6500 \times \mathrm{g}$ for $5 \mathrm{~min}$ at $4{ }^{\circ} \mathrm{C}$. The washing samples, worm incubation medium and homogenates of worms and mucosa were frozen for further use.

The protein content in the incubation medium and worm homogenate was determined using Lowry's method (Lowry et al., 1951).

\section{Measuring the proteolytic activity}

The total activity of alkaline proteinases in the tegumental washing samples and in the homogenate of the pike intestine mucosa was determined by the modified method of Alarcón using $0.3 \%$ (w/v) azocasein in Tris buffer, pH 7.5 as substrate (Alarcón et al., 2002). While preparing the control samples, equivalent volume of buffer solution was added to each sample instead of enzymatically active components. The substrate and enzymatically active sample were incubated for $60 \mathrm{~min}$ at $20-22{ }^{\circ} \mathrm{C}$. The reaction was stopped by adding $1 \mathrm{ml}$ of $0.3 \mathrm{M}$ trichloracetic acid (TCA) solution. The sediment of non-hydrolyzed protein was removed by centrifuging at $6500 \times \mathrm{g}$ for $5 \mathrm{~min}$. The color development proportional to enzymatic activities was measured in the supernatant at $440 \mathrm{~nm}$ using the Lambda 25 (PerkinElmer) spectrophotometer.

\section{Measuring the inhibitor activity}

When measuring the inhibitor activity of worms, the proteinase sources were the homogenate of pike intestine mucosa and commercial trypsin from porcine pancreas (MP Biomedicals, USA; activity 250 USP). Trypsin was used in concentrations $0.0025,0.005$, $0.0075,0.01$ and $1 \mathrm{mg} / \mathrm{ml}$ in Tris buffer ( $\mathrm{pH} \mathrm{7.5).} \mathrm{To} \mathrm{determine}$ the inhibitor activity, $50-150 \mu$ l of worm homogenate or incubation medium were added to the experimental medium containing $0.5 \mathrm{ml}$ of mucosa homogenate or trypsin solution of certain concentration, and incubated for $15 \mathrm{~min}$. Simultaneously, the same volume of buffer was added to the respective control sample. After the incubation, the proteolytic activity in the samples was determined as described above.

To identify the proteinase subclasses in washing samples $F_{1}-F_{3}$ obtained from the tegument of $T$. nodulosus, $50 \mu$ of the following 


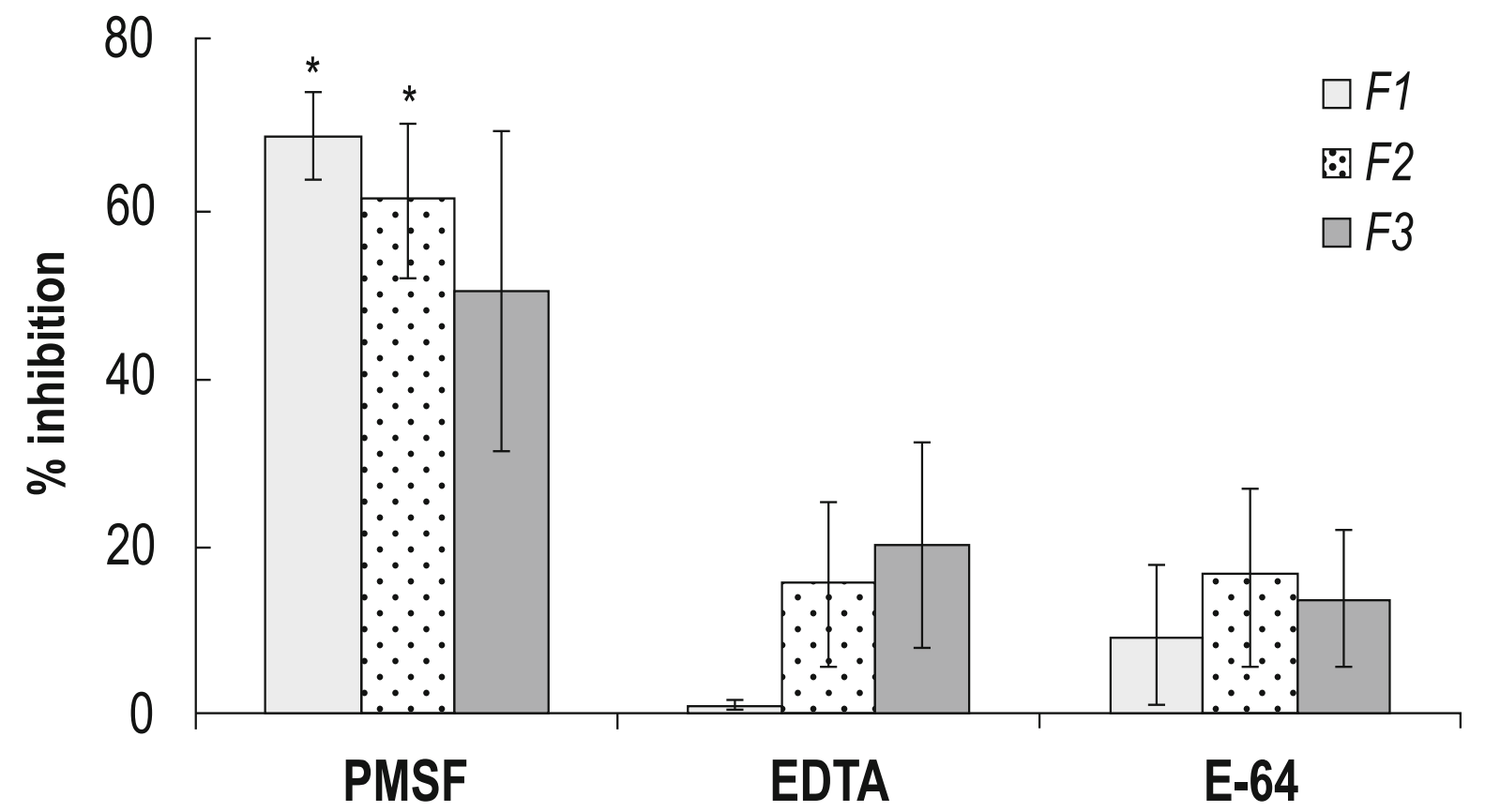

Fig. 1. Percent inhibition (mean $\pm \mathrm{SE}$ ) of proteolytic activity by various inhibitors in different fractions $\left(\mathrm{F}_{1}-\mathrm{F}_{3}\right)$ washed off $T$. nodulosus tegument ('significant inhibitory effect, $p<0.05)$.

Inhibitors ( $50 \mu \mathrm{l}$ of each) were added to each test sample: PMSF - inhibitor of serine proteinases (100 mM solution in DMSO), EDTA - metalloprotease inhibitor (0.5 M in $1 \mathrm{M} \mathrm{NaOH}$ ), and E-64 - inhibitor of cysteine (thiol) proteinases (1 mM in distilled water). Equal volumes (50 $\mu$ l) of Tris buffer (pH 7.5) were added to each control sample instead of inhibitor solution ( $100 \%$ inhibition means total suppression of enzyme activity). Fractions were washed off the worms by shaking them in $10 \mathrm{ml}$ of Ringer's solution: for the first 30 seconds $\left(F_{1}\right)$, for the next 15 minutes in fresh Ringer's solution $\left(F_{2}\right)$, and for the final 15 minutes in a new portion of Ringer's solution $\left(F_{3}\right)$. Seven randomly selected groups of worms were tested $(n=7)$.

inhibitors were used: (1) PMSF (phenyl-methyl-sulfonyl-fluoride) - inhibitor of serine proteinases, $100 \mathrm{mM}$ solution in DMSO (dimethyl sulfoxide); (2) EDTA (ethylenediaminetetraacetic acid) - metalloprotease inhibitor, $0.5 \mathrm{M}$ in $1 \mathrm{M} \mathrm{NaOH}$, and (3) E-64 - inhibitor of cysteine (thiol) proteinases, $1 \mathrm{mM}$ in distilled water.

Besides, to compare the inhibitor activity levels of $T$. nodulosus samples, the PMSF inhibitor activity in the pike intestine mucosa homogenate and trypsin solutions was measured.

The proteinase activity was expressed as the difference of spectrophotometer readings $(\Delta \mathrm{Abs})$ for the sample with substrate versus a blank sample per gram of wet worm, intestinal tissue or trypsin solution for a minute interval ( $\Delta \mathrm{Abs} / \mathrm{g} / \mathrm{min})$. Each biochemical assay was conducted in triplicate.

\section{Statistical analyses}

The results are given as means \pm SE. Inhibitory effects were tested using a one-way ANOVA with a post hoc Dunnet's test when comparing multiple means against a single control mean or with the Tukey's (HSD) test for multiple pairwise comparisons. The level of significant difference was set at $p=0.05$. Statistical analyses were carried out using the software package STATISTICA 6.0 (StatSoft, Inc., Tulsa, OK, USA).

\section{Results}

Proteolytic activity in tegumental washing samples

The research results show that proteolytic enzymes are washed off the worm's surface mainly to fraction $\mathrm{F}_{1}$, where the enzyme activity reached $0.49 \pm 0.03 \Delta \mathrm{Abs} / \mathrm{g} / \mathrm{min}$. In fractions $F_{2}$ and $F_{3}$, only low-level proteolytic activity has been detected $(0.003 \pm 0.001$ and $0.002 \pm 0.001 \Delta$ Abs $/ \mathrm{g} / \mathrm{min}$ respectively). It was demonstrated that PMSF notably reduces the activity of proteinases washed off the tegument. In fraction $F_{1}$, PMSF inhibits $68.9 \pm 5.0 \%$ of the activity (Fig. 1). On the contrary, no significant influence of EDTA and E-64 on the activity of desorbed proteinases was observed. In fractions $F_{2}$ and $F_{3}$, no significant effect of any of the studied inhibitors on proteinase activity was detected (Fig. 1).

The $\mathrm{pH}$ value and protein content in the studied samples

It was ascertained that after 24 hours of worm incubation the $\mathrm{pH}$ value in Ringer's solution decreases from 7.5 to $6.4 \pm 0.1$. At the same time, protein appeared in the incubation medium, and its content averaged $0.57 \pm 0.16 \mathrm{mg} / \mathrm{ml}$. The protein content in the homogenate of the studied cestodes reached $18.19 \pm 1.99 \mathrm{mg} / \mathrm{ml}$. Inactivation of proteolytic enzymes by T. nodulosus

It was found that both the incubation medium and the worm homogenate reduce the proteolytic activity in the intestinal mucosa 


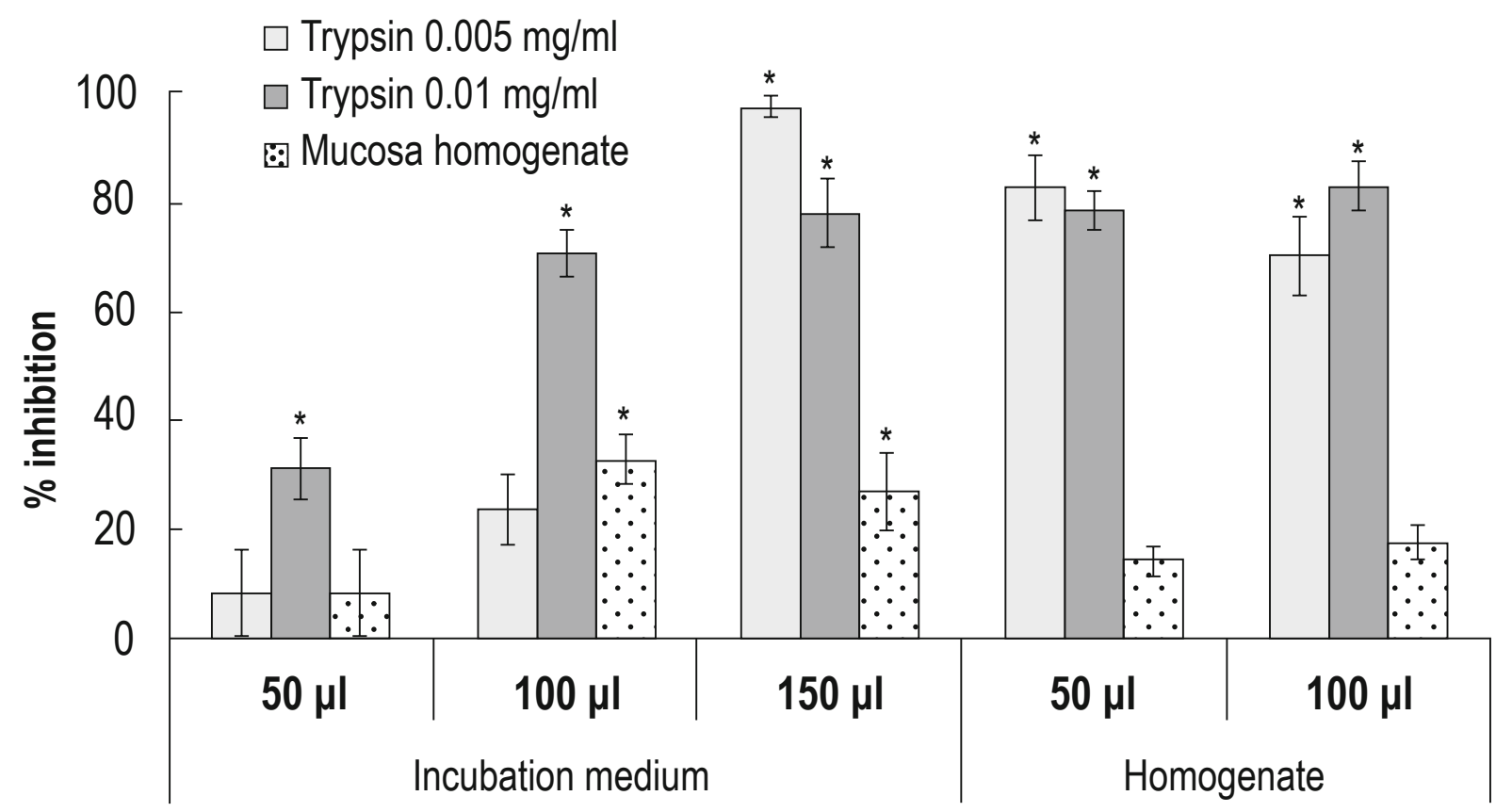

Fig. 2. Inhibitory action of $T$. nodulosus incubation medium and worm homogenate depending on sample volume (mean $\pm \mathrm{SE}$; *significant inhibition, $p<0.05$ ). The proteinase sources were commercial trypsin sample (MP Biomedicals, USA; activity $250 \mathrm{USP}$ ) with concentrations of $0.005 \mathrm{and} 0.01 \mathrm{mg} / \mathrm{ml}$ in Tris buffer (pH 7.5) and the homogenates of pike intestinal mucosa. The mucosa was homogenized, diluted with Ringer's solution in the ratio of 1:49 and then centrifuged at $6500 \times \mathrm{g}$ for 5 min at $4{ }^{\circ} \mathrm{C}$. Incubation medium is $10 \mathrm{ml}$ of Ringer's solution where the worms were kept for 24 hours at a temperature of $10^{\circ} \mathrm{C}$. The worm homogenates were diluted with Ringer's solution in the mass-volume ratio of 1:9 and centrifuged under the same conditions. In the experiments, 50 or $100 \mu$ l volumes of supernatant were used. Control is the activity of a certain trypsin solution (or mucosa homogenate) with 50,100 or $150 \mu$ l of Tris buffer (pH 7.5) added instead of the same volumes of enzymatically active components ( $100 \%$ inhibition means total suppression of enzyme activity). Numbers of groups of worms tested were 5 for the incubation medium $(n=5)$ and 11 for the homogenate $(n=11)$.

homogenate and the activity of trypsin at various concentrations as compared to the control (Fig. 2). The extent and significance of activity reduction depend on the source of proteolytic enzymes (homogenate or trypsin) and the studied sample (worm incubation medium or worm homogenate) (Fig. 2).

The comparison of percent inhibition for trypsin solution and intestinal mucosa homogenate shows that both the worm incubation medium and its homogenate have a stronger inhibitory effect on the trypsin activity than on the mucosa homogenate. The trypsin inhibition percentage varied from $23.9 \pm 6.1 \%$ to $97.7 \pm 1.9 \%$ depending on its concentration, as well on the source and volume of the inhibitor. Conversely, suppression of the proteolytic activity in the mucosa homogenate ranged from $14.4 \pm 2.8$ just to $33.0 \pm 4.6$ $\%$, and the inhibitory effects were significant only for some of the studied variants (Fig. 2).

The influence of various inhibitor sources on the activity of trypsin at a concentration of $0.01 \mathrm{mg} / \mathrm{ml}$ is shown in Fig. 3. Various volumes of the incubation medium and tapeworm homogenate significantly reduced the trypsin activity at this concentration. The efficacy of the inhibitors produced by the worm is comparable to that of the synthetic inhibitor PMSF. Besides, the detected effects were not dependent on the volume of the studied sample (Fig. 3).
When adding $50 \mu \mathrm{l}$ of worm homogenate to trypsin solutions of various concentrations, it was shown that the trypsin inhibition percentage depends on its concentration. A high degree of inhibition was found for trypsin concentrations of $0.005-0.01 \mathrm{mg} / \mathrm{ml}$. The observed effects are significant, $p<0.05$ (Fig. 4). At concentration of $0.0025 \mathrm{mg} / \mathrm{ml}$, the trypsin activity reduction was not significant, and at concentration of $1 \mathrm{mg} / \mathrm{ml}$ no inhibition of the enzyme activity by the worm homogenate was seen (Fig. 4). It should be noted that the activity of trypsin at concentration of $0.01 \mathrm{mg} / \mathrm{ml}$ was slightly higher than at $0.005 \mathrm{mg} / \mathrm{ml}$, but this difference was not significant $(p=0.414)$. The inhibitory action of $50 \mu \mathrm{l}$ of homogenate tested at trypsin concentrations of $0.005-0.01 \mathrm{mg} / \mathrm{ml}$ varied within a narrow range (from $78.6 \pm 3.0$ to $83.8 \pm 7.2 \%$ ) amounting to approximately $80 \%$.

\section{Discussion}

Proteolytic activity in tegumental washing samples

The results of studying the desorption of proteinases from the tegument of $T$. nodulosus agree with the earlier obtained data on desorption of hydrolytic enzymes from the cestode tegument: the major activity is represented by the easily desorbed fraction 


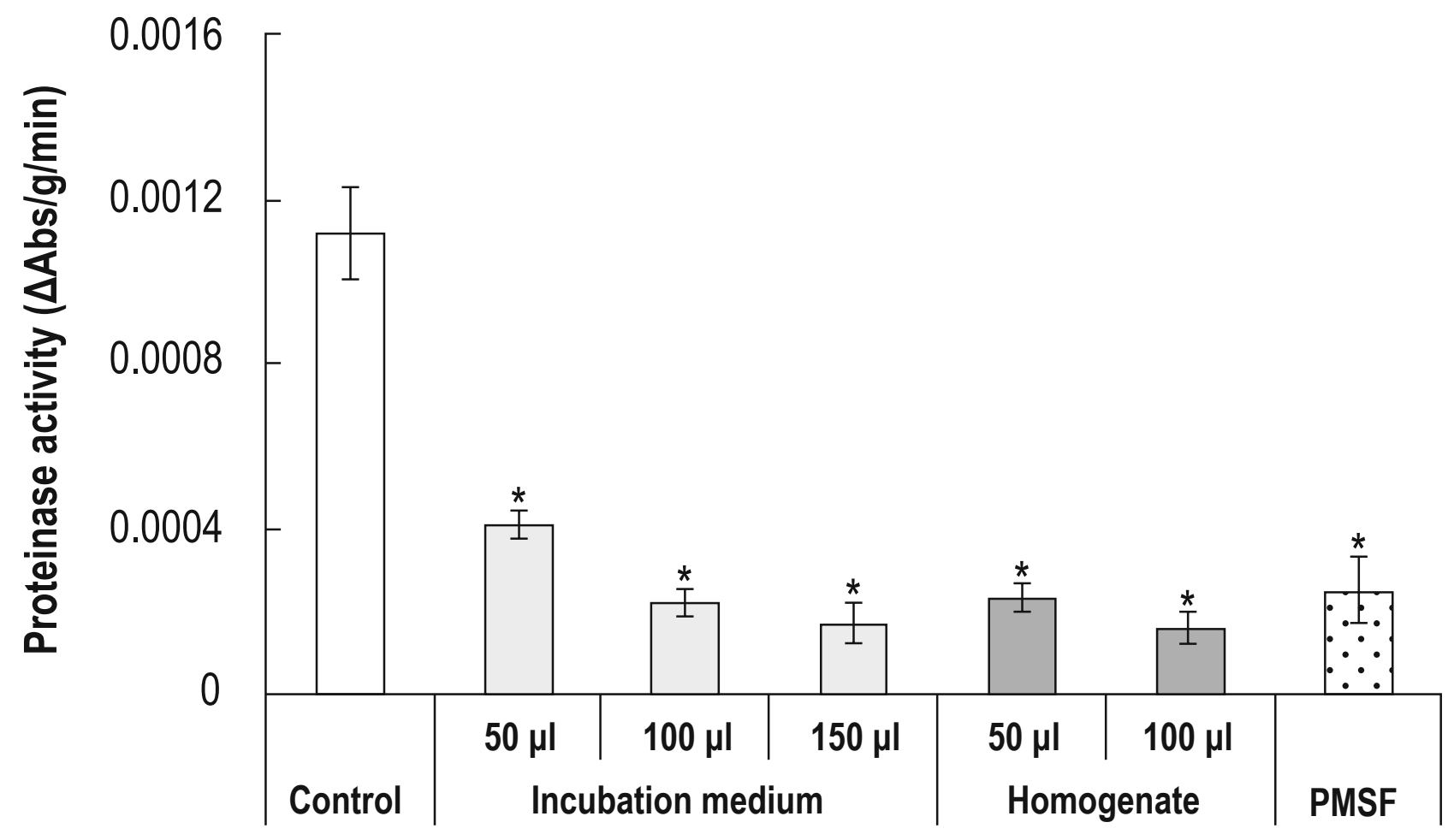

Fig. 3. Inhibitory effect of various volumes of $T$. nodulosus incubation medium, worm homogenate and PMSF on the activity of commercial trypsin samples ( $0.01 \mathrm{mg} / \mathrm{ml}$ ) (mean $\pm \mathrm{SE}$; *significant difference from a single control mean, $p<0.05$ ).

The proteinase activity is the difference of spectrophotometer readings ( $\triangle \mathrm{Abs}$ ) for the sample with substrate versus a blank sample per gram of trypsin solution for a minute interval $(\triangle \mathrm{Abs} / \mathrm{g} / \mathrm{min})$. Control is the activity of commercial trypsin sample $(0.01 \mathrm{mg} / \mathrm{ml})$. PMSF is the inhibitor of serine proteinases $(50 \mu \mathrm{l}$ per each sample, $100 \mathrm{mM}$ solution in DMSO). Incubation medium is $10 \mathrm{ml}$ of Ringer's solution, where the worms were kept for 24 hours at a temperature of $10^{\circ} \mathrm{C}$. The worm homogenate was diluted with Ringer's solution in the mass-volume ratio of $1: 9$ and centrifuged at $6500 \times \mathrm{g}$ for 5 min at $4{ }^{\circ} \mathrm{C}$. In the experiments, 50 or $100 \mu$ l volumes of supernatant were used. Numbers of groups of worms tested were 5 for the incubation medium $(n=5)$ and 11 for the homogenate $(n=11)$.

characterizing the activity of the host's enzymes (Izvekova et al., 1997). It is known that cestodes not only produce their own hydrolases but also capture and adsorb the host's enzymes, including proteinases (Halton, 1997; Izvekova et al., 1997; Kuz'mina et al., 2000; Dalton et al., 2004; Izvekova, 2006). The inhibitor analysis shows that the main part of enzymes adsorbed on the tegument are serine proteinases. In the pike intestine, the highest percentage of proteolytic activity is also associated with serine proteinases and, according to some data, is 56.4 and $59.6 \%$ in pikes uninfected and infected by $T$. nodulosus respectively (Izvekova \& Solovyev, 2016).

Inactivation of proteolytic enzymes by cestodes

The obtained data show that T. nodulosus cestodes produce substances suppressing the activity of proteinases found in the host intestine mucosa homogenate, as well as the activity of trypsin solutions of different concentrations. According to some authors, enzyme inactivation is a marker of inhibitor production and secretion that requires no proof of the actual inhibitor presence (Matská- si \& Juhász, 1977). In our study, the comparable levels of trypsin activity reduction by the synthetic inhibitor PMSF and inhibitors produced by the worm show that the cestode's inhibitors inactivate serine proteinases (Fig. 3). This agrees with the data obtained by other authors showing the production of serine proteinase inhibitors by cestodes (Pappas, 1978; Pappas \& Uglem, 1990). Serine proteinase inhibitors are among the key components of secretory products in many parasite species (Zimic et al., 2007). They play an important role in the parasite's survival because of their ability to inhibit the host's enzymes, and are normally present in the microenvironment and/or secreted by the immune effector cells (Zang \& Maizels, 2001). These inhibitors regulate the protease activity and control various processes related to it. Particularly, they play an important role in protecting the parasite from the host's digestive enzymes and, according to some authors, contribute to host specificity (Hawley \& Peanasky, 1992). In the current study we established that $T$. nodulosus preparations had greater inhibitory effect on the trypsin activity than on the proteolytic activity of pike mucosa homogenate (Fig. 2). This is probably due to the fact 


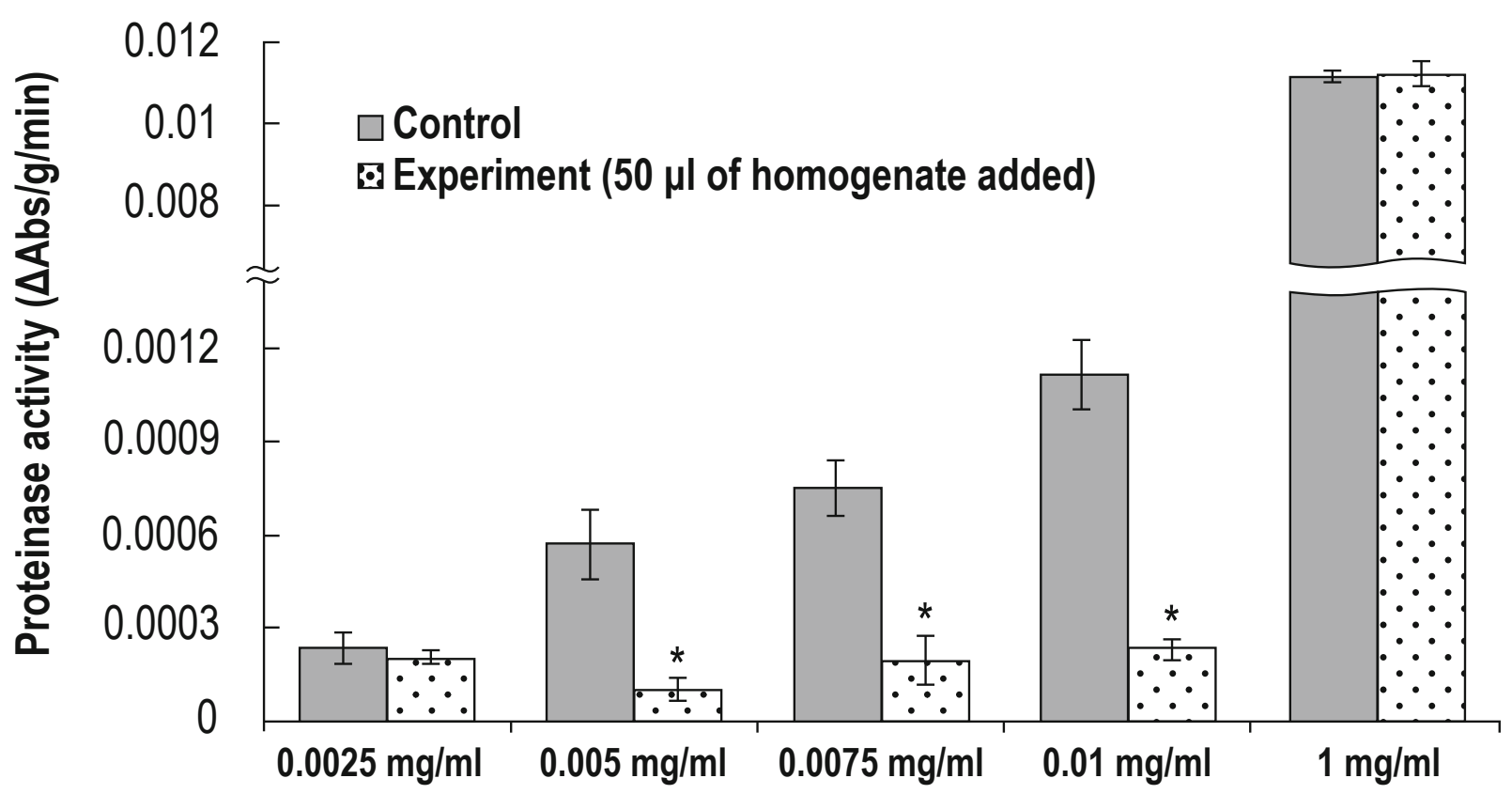

Trypsin concentrations

Fig. 4. Suppressive effect of $T$. nodulosus homogenate $(50 \mu \mathrm{l})$ on trypsin activity at various concentrations. Error bars indicate SE (*significant difference from respective control values, $p<0.05$ ).

The proteinase activity is the difference of spectrophotometer readings $(\triangle \mathrm{Abs})$ for the sample with substrate versus a blank sample per gram of trypsin solution for a minute interval $(\Delta \mathrm{Abs} / \mathrm{g} / \mathrm{min})$. Control is the activity of commercial trypsin sample at various concentrations $(0.0025-1 \mathrm{mg} / \mathrm{ml})$ with $50 \mu \mathrm{l}$ of Tris buffer ( $\mathrm{pH} 7.5)$ added to the reaction mixture. In the experiment, the activity of commercial trypsin sample in a certain concentration was determined with $50 \mu \mathrm{l}$ of worm homogenate added. The worm homogenate was diluted with Ringer's solution in the mass-volume ratio of $1: 9$ and centrifuged at $6500 \times \mathrm{g}$ for $5 \mathrm{~min}$ at $4{ }^{\circ} \mathrm{C}$. In the tests, $50 \mu \mathrm{l}$ of supernatant was used. Numbers of groups of worms tested was $11(n=11)$.

that the proteinase activity in the intestine is provided not only by trypsin, but also by chymotrypsin and various peptidases (Solovyev et al., 2015). The study of the inhibitory capacity of $H$. diminuta also showed incomplete inhibition of the host's proteolytic activity by the worms, and great variability of the obtained data (Pappas \& Uglem, 1990).

The detected effect of proteinase inhibition by the worm's incubation medium as well as by its homogenate means that the parasite spontaneously excretes the inhibitor into the medium (Fig. 2, 3). However, the increase in the volume of incubation medium and homogenate does not lead to significant changes in the proteinase inactivation level (Fig. 3). The present study ascertained that after 24 hours protein is detected in the T. nodulosus incubation medium. This may be associated with the regular renewal of the glycocalix (Oaks \& Lumsden, 1971), as well as with secretion of proteinase inhibitor into the surrounding medium. It is also known that proteinase inhibitors in many parasitic worms are of protein nature (Knox, 2007).

The insignificant influence of cestode homogenate on trypsin activity at its very low $(0.0025 \mathrm{mg} / \mathrm{ml})$ and considerably high $(1 \mathrm{mg} /$ $\mathrm{ml}$ ) concentrations (Fig. 4) may be due to the insufficient sensitivity of the method in the former case, and to "masking" the inhibition effect at high concentration and, respectively, high activity in the latter case. A reduction of the inhibitory activity as the enzyme concentration grows is also observed in $\mathrm{H}$. diminuta (Pappas \& Read, 1972a; Pappas, 1978).

Our experiment conditions (keeping the worms in Ringer's solution to get an incubation medium, and subsequent preparation of the worm homogenate) make it possible to suppose that secretion of proteinase inhibitors is not induced by the presence of proteinases in the medium, but instead, they are spontaneously synthesized by the parasite. A similar assumption was made earlier when exploring the soluble fraction of the isolated $H$. diminuta tegument brush border (Pappas \& Uglem, 1990). The authors demonstrated that this fraction contains substances inhibiting the proteolytic and amidase activity of bovine trypsin and some proteolytic enzymes of the host's small intestine (Pappas \& Uglem, 1990).

Possible mechanisms of proteinase inhibition in cestodes: facts and hypotheses

It should be noted that the available information on cestodes inhibiting proteolytic enzymes is somewhat contradictory. Thus, there are data confirming the inactivation of proteases during interaction with live worms. It was shown that the adsorptive surface of worms interacts with the host's enzymes altering their activity. For instance, during incubation of $H$. diminuta with trypsin, $a-$ and 
$\beta$-chymotrypsin in vitro, the specified enzymes were inactivated on the worm's surface, but no secretion of the active inhibitor into the surrounding medium was detected (Pappas \& Read, 1972a,b). According to these authors, inactivation of trypsin and chymotrypsin was more dependent on the worm's weight than on its surface area. This may be associated with the renewal of glycocalyx that occurs in H. diminuta in 6 hours (Oaks \& Lumsden, 1971). Later it was evidenced that trypsin is more likely adsorbed on the worm's surface than absorbed by the worm, however, the enzyme adsorption is not associated with its inactivation (Schroeder \& Pappas, 1980; Schroeder et al., 1981).

At the same time it was found that the isolated membrane of the $H$. diminuta tegument is not resistant to the action of proteolytic enzymes and does not affect their activity. Therefore it was assumed that inactivation of proteolytic enzymes requires a metabolically active, dynamic membrane, while an isolated tegument membrane sample does not meet these requirements (Pappas, 1987). Our findings of proteinase inhibition by the incubation medium and cestode homogenate show that inhibitors are secreted by worms. The isolation of tegument brush border is possibly accompanied by inhibitor loss at the stage of centrifuging used to obtain the samples. When studying the inhibitory capacity of $\mathrm{H}$. diminuta inhabiting the rat intestine, it was found that salt solution with initial $\mathrm{pH}$ values from 5.5 to 10.0 is acidified by the worms to pH 5.0 (Uglem \& Just, 1983). It was supposed that intestinal parasites may protect themselves from being digested by host enzymes by regulating the ambient $\mathrm{pH}$, or by producing trypsin inhibitors, or both (Uglem \& Just, 1983). However, we cannot fully agree with this supposition. In particular, for fish it was found that the activity of alkaline proteinases is displayed within the $\mathrm{pH}$ range from 5 to 10 (Solovyev et al., 2015), while during the incubation of $T$. nodulosus in Ringer's solution the $\mathrm{pH}$ values decrease to $6.4 \pm 0.1$. The reduction of $\mathrm{pH}$ values in $T$. nodulosus incubation medium is mainly related to secretion of lactic acid into this medium (Izvekova, 2001). Like most endoparasites, when having access to unlimited food resources, cestodes use shortcut metabolic pathways and perform incomplete food substrate oxidation (Soprunov, 1987). As a result, they produce and secrete a lot of partly oxygenated short-chain organic acids (lactic, propionic, acetic) lowering the host intestine $\mathrm{pH}$. This suppresses the host intestine transport functions, while the worm's glucose carriers work better at lower pH values (Halton, 1997; Dalton et al., 2004). Thus, parasites reach high efficiency and competitiveness of transportation systems, while $\mathrm{pH}$ reduction in the intestine does not cause a significant negative effect on the functioning of the host's digestive enzymes.

Although the available information, including our data, is somewhat contradictory, it is obvious that cestodes inhabiting the intestine of their definitive hosts are able to suppress the activity of host proteinases. The secretion of host enzyme inhibitors by parasites proves that the inhibitors play an important role in the parasite's life. Parasites produce inhibitors to survive and not be hydrolyzed by the host's proteinases. The dualism of helmint adaptation to the living conditions is manifested in the interaction with the host's enzymes on the micro-level: the parasite uses the enzymes to hydrolyze the protein components of food on the one hand, and to inhibit proteinases on the other hand. The obtained data supplement the view of $T$. nodulosus functioning at the adult worm stage and its relationship with the definitive host.

Thus, the study shows that the main proteolytic activity in washings off the T. nodulosus tegument is represented in the easily desorbed fraction most likely characterizing the host enzyme activity. The activity of this fraction is mainly related to serine proteinases. At the same time, it is shown that T. nodulosus cestodes can inhibit host proteinases and commercial trypsin samples. Both the worm incubation medium and their homogenate have inhibitory activity. Obviously, proteinase inhibitor secretion is not induced by the presence of proteinases in the external medium, but spontaneously performed by the parasite. The inhibitor produced by the cestode appears to be trypsin-specific.

\section{Acknowledgements}

This work was supported by the Russian Foundation for Basic Research (grant number 15-04-02474).

\section{References}

Alarcón, F.J., Martínez, T.F., Barranco, P., Cabello, T., Díaz, M., MoYano, F.J. (2002): Digestive proteases during development of larvae of red palm weevil, Rhynchophorus errugineus (Olivier, 1790) (Coleoptera: Curculionidae). Insect Biochem. Mol. Biol., 32: 265 - 274. DOI: 10.1016/s0965-1748(01)00087-x

Dalton, J.P., Skelly, P., Halton, D.W. (2004): Role of the tegument and gut in nutrient uptake by parasitic platyhelminths. Can. J. Zool., 82: 221 - 232. DOI: 10.1139/z03-213

Delaney, A., Williamson, A., Brand, A., Ashcom, J., Varghese, G., Goud, G.N., Hawdon, J.M. (2005): Cloning and characterisation of an aspartyl protease inhibitor (API-1) from Ancylostoma hookworms. Int. J. Parasitol., 35: 303 - 313. DOI: 10.1016/j.ijpara.2004.11.014

DuBovskaYA, A.YA. (1973): A study of proteolytic activity in some cestode species. Parazitologiya, 7: 154 - 159 (In Russian)

DzIK, J.M. (2006): Molecules released by helminth parasites involved in host colonization. Acta Biochim. Pol., 53(1): 33 - 64

HALTON, D.W. (1997): Nutritional adaptations to parasitism within the Platyhelminthes. Int. J. Parasitol., 27: 693 - 704. DOI: 10.1016/ S0020-7519(97)00011-8

Hawley, J.H., PeAnasky, A.J. (1992): Ascaris suum: Are trypsin inhibitors involved in species specificity of ascarid nematodes? Exp. Parasitol., 75: 112 - 118

Hwang, J.H., Lee, W.G., Na, B.K. et al. (2009): Identification and characterization of a serine protease inhibitor of Paragonimus westermani. Parasitol. Res., 104: 495 - 501. DOI: 10.1007/ s00436-008-1219-6 
IZVEKOVA, G.I. (2006): The nutritional adaptations of lower cestodes - fish parasites. Usp. Sovrem. Biol., 126: 630 - 642 (In Russian) IzVEKovA, G.I. (2001): Triaenophorus nodulosus (Cestoda, Pseudophyllidea): final stages of carbohydrate metabolism. Helminthologia, 38: $23-27$

Izvekova, G.I., Kuperman, B.I., Kuz'mina, V.V. (1997): Digestion and digestive-transport surfaces in cestodes and their fish host. Comp. Biochem. Physiol. A., 118: 1165 - 1171. DOI: 10.1016/S03009629(97)00040-6

IzVEKOVA, G.I., Solovyev, M.M. (2016): Characteristics of the effect of cestodes parasitizing the fish intestine on the activity of the host proteinases. Biol. Bull., 43: 146 - 151. DOI: 10.1134/ S1062359016010076

KAGEYAMA, T. (1998): Molecular cloning, expression and characterization of an Ascaris inhibitor for pepsin and cathepsin E. Eur. J. Biochem., 253: 804 - 809. DOI: 10.1046/j.1432-1327.1998.2530804.x KLIMENKO, V., ĶËNINA, V. (1971): On the influence of phylogeny and ecology on some biochemical mechanisms of helminth adaptation. Latvijas Zinatnu akademijas vestis, 11: 93 - 96. (In Russian) KNox, D.P. (2007): Proteinase inhibitors and helminth parasite infection. Parasite Immunol., 29: 57 - 71. DOI: 10.1111/j.13653024.2006.00913.x

Kuz'mina, V.V., Izvekova, G.I., Kuperman, B.I. (2000): Peculiarities of nutrition physiology in cestodes and their host-fish. Usp. Sovrem. Biol., 120: 384 - 384. (In Russian)

LI, A.H., Moon, S.-U., PARK, Y.-K. et al. (2006): Identification and characterization of a cathepsin L-like cysteine protease from Taenia solium metacestode. Vet. Parasitol., 141: 251 - 259. DOI: 10.1016/j.vetpar.2006.05.015

Lowry, O.H., Rosebrough, N.J., Farr, A.L., Randall, R.J. (1951): Protein measurement with the Folin phenol reagent. J. Biol. Chem., 193: 265 - 275

MATSKÁSI, I. (1984): The effect of Bothriocephalus acheilognati infection on the protease and a-amylase activity in the gut of carp fry. Symp. Biol. Hung., 23: 119 - 125

MATSKÁSI, I., JUHÁSZ, S. (1977): Ligula intestinalis (L., 1758): Investigation on plerocercoids and adults for protease and protease inhibitor activities. Parasitol. Hung., 10: 51 - 60

Molehin, A.J., Gobert, G.N., Mcmanus, D.P. (2012): Serine protease inhibitors of parasitic helminths. Parasitology, 139: 681 - 695. DOI: $10.1017 /$ S0031182011002435

OAKS, J., Lumsden, R.D. (1971): Cytochemical studies on the absorptive surfaces of cestodes. V. Incorporation of carbohydrate containing macromolecules into tegument membranes. J. Parasitol., 57: $1256-1268$
Pappas, P.W. (1987): Hymenolepis diminuta: interactions of the isolated brush border membrane with proteolytic enzymes. Exp. Parasitol., 64: 38 - 47

PAPPAS, P.W. (1978): Tryptic and protease activities in the normal and Hymenolepis diminuta-infected rat small intestine. J. Parasitol., 64: $562-564$

PapPas, P.W., Read, C.P. (1972a): Trypsin inactivation by intact $\mathrm{Hy}$ menolepis diminuta. J. Parasitol., 58: 864 - 871

Pappas, P.W., ReAd, C.P. (1972b): Inactivation of $\alpha$ - and $\beta$-chymotrypsin by intact Hymenolepis diminuta (Cestoda). Biol. Bull., 143: $605-616$

Pappas, P.W., Uglem, G.L. (1990): Hymenolepis diminuta (Cestoda) liberates an inhibitor of proteolytic enzymes during in vitro incubation. Parasitology, 101: 455 - 464

RAsCón, A.A.JR, MCKERROW, J.H. (2013): Synthetic and natural protease inhibitors provide insights into parasite development, virulence and pathogenesis. Curr. Med. Chem., 20: 3078 - 3102. DOI: 10.2174/0929867311320250005

ReICHENBACh-KlinKe H.-H., ReICHENBACH-KLINKE K.-E. (1970): Enzymuntersuchungen an Fishen.II. Trypsin- und a-amylase-Inhibitoren. Arch. Fishereiwiss., 21: $72-76$

Schroeder, L.L., Pappas, P.W. (1980): Trypsin adsorption by Hymenolepis diminuta (Cestoda). J. Parasitol., 66: 49 - 52

Schroeder, L.L., Pappas, P.W., Means, G.E. (1981): Trypsin inactivation by intact Hymenolepis diminuta (Cestoda): some characteristics of the inactivated enzyme. J. Parasitol., 67: 378 - 385

ShISHOVA-KasatochKINA, O.A., LeUtSKAYA, Z.K. (1979): Biochemical aspects of relations between helminth and host. Moscow, Nauka, 280 pp. (In Russian)

Solovyev, M.M., Kashinskaya, E.N., IzVekova, G.I., Glupov, V.V. (2015): pH values and activity of digestive enzymes in the gastrointestinal tract of fish in lake Chany (West Siberia). J. Ichthyol., 55: 251 - 258. DOI: 10.1134/S0032945215010208

Soprunov, F.F. (1987): Molecular basis of parasitism. Moscow, Nauka, 224 pp. (In Russian)

UGLEM, G.L, JUst, J.J. (1983): Trypsin inhibition by tapeworms: antienzyme secretion or pH adjustment? Science, 220: 79 - 81.

ZANG, X., MAIZELS, R.M. (2001): Serine proteinase inhibitors from nematodes and the arms race between host and pathogen. Trends Biochem. Sci., 26: 191 - 197. DOI: 10.1016/S09680004(00)01761-8

Zimic, M.J., Infantes, J., LóPEZ, C. et al. (2007): Comparison of the peptidase activity in the oncosphere excretory/secretory products of Taenia solium and Taenia saginata. J. Parasitol., 93: 727 - 734. DOI: 10.1645/GE-959R.1 